\title{
Carbon Quota and Efficiency Power Plants Implementation Decision
}

\author{
Yiping Zhu*, Yue Jin \\ Management School, Nanchang University, Nanchang City, Jiangxi Province, 330031, China
}

Received: 28 September 2020

Accepted: 10 April 2021

\begin{abstract}
Efficiency Power Plant (EPP) is a package of power demand side projects with zero emission, zero pollution and other advantages. In the process of implementing EPP, enterprises not only save electricity, but also reduce carbon emissions, while meanwhile increase the cost of R\&D and equipment. Therefore, it is very necessary to study relationships between carbon quota and EPP implementation decision. In this paper, we build the profit functions of three different types of enterprises implementing EPP and analyze the relationship of main parameters, such as the probability of implement EPP, electricity saving, income, cost and carbon quota, and refine 11 relative results. At last we use 'Maple' software to verify the validity of the results, and carry out an empirical analysis of a case in China to prove the practicability of the relationship analysis results. The conclusion shows that under the carbon quota trading environment, enterprises should tend to implement EPP, and increase investment in R\&D and acquisition of EPP, and need adjust the intensity of implementing EPP according to the change of carbon quota, unit carbon quota income, to obtain higher income.
\end{abstract}

Keywords: Efficiency Power Plants, implementation decision, carbon quota, relationship analysis, Maple

\section{Introduction}

Background

Demand Side Management (DSM) is to let power users manage their own enterprise electricity situation through the construction of electricity fine management platform. Efficiency Power Plant (EPP) is a representative DSM energy efficiency resource project. EPP can be considered as a collection of some DSM energy efficiency resource projects with combination. EPPs use high-efficiency electrical equipments and

*e-mail: zhuyipingnet@ncu.edu.cn products, based on the energy-saving transformation plan of an industry or a regional enterprise, to form a regional electricity utilization efficiency optimization in different ways, which has the same important significance with the construction of new power plant.

Over the past 10 years, the development of DSM has achieved abundant energy conservation and emission reduction effects and formed a certain scale. For example, the State Grid Energy Research Institute of China counts that the generation capacity of DSM project is 640.7 billion $\mathrm{kWh}$ in China of 2011-2015, and estimates 2016-2020 is 1.3254 trillion $\mathrm{kWh}$. It can reach 1.9661 trillion $\mathrm{kWh}$ during the period of 2010-2020, equivalent to a reduction of $22,598 \mathrm{kWh}$ in generation capacity and nearly 57 billion USD in investment compared with the conventional power plants [1]. 
Chinese government introduced a carbon quota management system [2], which has a significant impact on the implementation of EPP. Under the carbon quota system, enterprises must control the greenhouse gases emissions, mainly carbon dioxide $\left(\mathrm{CO}_{2}\right)$. The implementation of EPP can not only reduce power consumption, but also reduce carbon emissions, which to some extent improves the willingness of enterprises to implement EPP [3]. Moreover, as the EPP grew in size, massive fiscal and tax subsidies became unsustainable, carbon quotas became the government's main means of control carbon emissions.

In this paper, on the basis of predecessors' research summarized, we further combine government carbon quota with EPP implementation decision, through the establishment of the profit functions, analyze the decisions of enterprises under different carbon quota, and verify the correctness and rationality of the results through system simulation. This paper aims to provide a reference for enterprises to make correct decisions under different carbon quota in case of implementing EPPs.

\section{Literature Review}

EPP and DSM are hot topics in energy management, as they grew in size, encountered economic, technological and managerial problems in development process [4]. Thus most scholars prefer to focus on the three aspects of EPPs, such as in the economic field, billing [5], pricing [6] and cost-benefit analysis [7]; in the field of mathematics, such as scheduling [8] and planning [9], energy efficiency [10-12]; in the field of technology, such as renewable energy [13], smart distribution system [14] and others [15].

Game-theoretical analysis is commonly used in the decision-making of participants. Under the carbon emission constraint and trading mechanism, scholars have made some research achievements in game analysis of physical power plants. Fernandez and Hossain [16] presented an improved game-theoretic DSM framework for a neighborhood area to provide cost savings for the consumer and reduce the PAR for the neighborhood. Wu and Zhang [17] constructed and analyzed the noncooperative game, farmer-broker cooperative game, and broker-biomass power plant cooperative game under government incentives for Agribiomass power generation supply chain in China. Zhang and Cao [18] explored the evolutionary process of electricity market players considering energy storage technology, found the role of "Advanced Imitators" leaded the strategy of building energy storage changes. Literature [19] and [20] respectively applied game analysis to waste heat recovery energy supply chain and environmental efficiency analysis of China's power generation enterprises. However, there are still big differences between Entity Power Plants and Efficiency Power Plants. In particular, EPP can reduce electricity usage and carbon emissions at the same time, so there are many differences between the two decision-making mechanisms. Therefore, practical analysis of the decision-making mechanism of EPP is needed.

Among the field of energy management, the decision analysis of low-carbon investment behavior is meaningful and necessary. Rai and Beck [21] stated the importance of using behavioral science to address the persistent gaps between the technical potential of low carbon technologies and the actual adoption of these technologies. The decision analysis in low carbon environment is derived from the low-carbon supply chain research. Du et al. [22] conducted a decision analysis and gave low-carbon supply policies for supply chain management [23]. Chen et al. [24] investigated a practical demand side management scenario where the selfish consumers compete to minimize their individual energy cost through scheduling their future energy consumption profiles using an aggregative approach. $\mathrm{Li}$ et al. [25] examined the influences of different structures on the optimal decisions and performance of a low-carbon closed-loop supply chain (CLSC) with price and carbon emission level dependent market demands. Then the scholars put forward the behavior of each participant in low-carbon investment. Du et al. [26] considered the emission cap of emissiondependent manufacturer allocated by the government as a kind of environmental policy and formally investigated its influence on decision-makings within the concerned emission-dependent supply chain as well as distribution fairness in social welfare. Luo et al. [27] derived the optimal solutions for the two manufacturers in the purely competitive and co-opetitive market environments respectively. Huang et al. [28] proposed a simplified multi-energy system optimization method to assist stakeholders to participate in technoeconomic analysis process. Sun et al. [29] constructed a Stackelberg model (dominated by manufacturers) under both centralized and decentralized decisions considering the lag time of emission reduction technologies and the low-carbon preferences of consumers. Zhu and Pan et al. [30] investigated how to optimize the strategy of low carbon investment for suppliers and manufacturers in supply chains, and discuss the impacts of various factors on evolutionarily stable strategies. Arai et al. [31] proposed a comprehensive framework for evaluating the performance of demand-side actors in a demand-side management system using each control scheme according to both communication availability and sampling frequency. Liu et al. [32] proposed a scenario for DSM programs to schedule household energy consumption considering bidirectional energy trading of PEVs by a Bayesian approach. Mahmoudi et al. [33] evaluated performance of Iranian thermal power plants combined with multivariate data analysis techniques, Shannon entropy and the technique for order of preference by similarity to ideal solution. Dou et al. [34] established a dispatching optimization model of regional integrated power and gas energy system, and analyzed the node energy price through the node 
energy balance equation, as well as a demand response model.

Implementing EPP is a special low carbon behavior, which can not only reduce carbon emissions, but also reduce electricity consumption. Therefore, the decision analysis of EPP needs to consider both low carbon and power saving benefits. The author puts forward in previously published research a game model of EPP implementation by government and enterprise, but it is far from enough [35]. Research on decision analysis among EPP enterprises is likewise important, but unfortunately, there is a lack of research on this aspect, especially about the EPP implementation decision with carbon quotas and carbon reduction benefits. Above all, the literature that analyzes the decision analysis among EPP enterprises urgently needs to be supplemented. Therefore, this study of relationship analysis for EPP implementation decision and carbon quota is innovative and of practical value.

\section{Theoretical Basis}

\section{EPP}

EPP is a packaged set of DSM items or collections. EPPs realize energy saving transformation of energyconsuming equipment, and the energy saved is equivalent to the electricity generated by conventional coal-fired power plants [8]. Compared with conventional power plants, EPPs are designed to save electricity, not produce electricity. Although a EPP is not an entitative power plant, compared with power generation resources, it has the same importance in the optimal allocation of regional power supply and demand resources. It is an effective and convenient way to realize energy conservation and emission reduction and control power consumption [36]. EPPs have many advantages, such as zero emission, zero pollution, non-land occupation and non-construction cost. Based on these advantages, EPPs can be used to optimize regional power resource allocation and improve the reliability and stability of power system.

Table 1 compares fuel consumption, pollution emissions, and cost comparisons between EPPs and conventional power plants. The conventional power plant in the table takes a typical coal-fired power plant with an installed capacity of $300,000 \mathrm{~kW}$ as an example, and the annual utilization hour of its power generation equipment is about $5000 \mathrm{~h}$.

\section{Carbon Quota}

Carbon quota refers to the greenhouse gas emission reduction targets that must be completed according to the regulations. For EPP, it refers to the carbon dioxide emission reduction during the implementation of EPP. Many scholars have conducted researches on carbon quota, but they almost took carbon quota as a constraint condition, and few literatures have studied it as an endogenous variable. Carbon cap-and-trade was first proposed by J.H. Dales [37] in his book "Pollution, Property and Price", which pointed out that the government could consider the pollution as a transfer of the right through the process of mutual trading of emission rights by enterprises and the regulation of the market, so as to improve the efficiency of energy use. At present, carbon quota trading system is a relatively effective incentive means in the market, which can urge enterprises to take emission reduction measures. There are three typical distribution methods: free distribution, priced sale and full market [38]. There are mainly four typical carbon emission trading systems in the world [39], namely the European Union Carbon Emission Trading System (EUETS), the United States Regional Greenhouse Gas Initiative (RGGI), Australia's New South Wales Greenhouse Gas Emission Reduction System (NSWGGAS) and Japan's Tokyo Carbon Emissions Trading System (Tokyo ETS).

\section{Material and Methods}

\section{The Behavior of Implementing EPP}

In China, the initial government subsidy is one of impetus of the enterprises implementing EPPs. With the increase the size of the EPP, government financial subsidies began to gradually withdraw from the market, and carbon quota as another kind of subsidies for the development of enterprises began to appear. The government sets different carbon quota levels according to the ability to implement EPP, thus encouraging the development of EPP. The government stipulates a certain amount of carbon quota at the initial stage of the enterprise. With the implementation of EPP, the government will subsidize a certain amount of carbon quota for unit reduction of electricity consumption. When not implementing EPP, a certain amount of carbon quota will be consumed in normal enterprise production. At the end of each year, the total amount of carbon quota of the enterprise is accounted. The excess carbon quota can be exported by the enterprise to obtain funds. If the excess carbon quota is less than zero, the enterprise needs to buy excess carbon quota from other enterprises, or it will have to pay high compensation to the government.

This paper takes the government carbon quota level as an endogenous variable and studies how enterprises should formulate EPP implementation decision with the change of carbon quota level to ensure the maximization of their own income. For enterprises that choose to implement EPP, we analyze the carbon quota level that enterprises will reach the critical value of $R \& D$ investment, and with the constant change of carbon quota level, we research how the electricity reduced and the income obtained by implementing EPP will change with the change of carbon quota; For enterprises not choose to implement EPP, we study the carbon quota 
Table 1. Comparison of conventional power plants and efficiency power plants.

\begin{tabular}{|c|c|c|}
\hline Parameter & Conventional power plants & Efficiency power plants \\
\hline Capacity $(10,000 \mathrm{kV})$ & 30 & 30 \\
\hline Electricity produced/saved per year (one billion million $\mathrm{kWh})$ & 1.5 & 1.5 \\
\hline Fuel (standard coal) consumption $(\mathrm{g} / \mathrm{kWh})$ & 340 & 0 \\
\hline $\mathrm{CO}_{2}$ emission $(\mathrm{g} / \mathrm{kWh})$ & 940 & 0 \\
\hline $\mathrm{SO}_{2 .}$ emission $(\mathrm{g} / \mathrm{kWh})$ & 4 & 0 \\
\hline Average power generation and supply cost $($ dollar $/ \mathrm{kWh})$ & $2.2 \sim 2.8$ & 1 \\
\hline
\end{tabular}

level that enterprises will start to tend to implement $\mathrm{EPP}$, and research what extent will them continue to ignore EPP. For enterprises that are uncertain whether to implement EPP or not, we study how should they make EPP decision with the change of carbon quota, that is, determine the tendency (probability) of implementing EPP, so as to maximize their own income, and research the change trend of enterprise output and income with the change of carbon quota.

\section{Assumptions}

\section{(1) Subject}

There are three different types of enterprises, namely, enterprise $E_{1}$ which always implements EPP, enterprise $E_{2}$ which never implements EPP, and Enterprise $\mathrm{E}_{3}$ which implements EPP as the case may be.

(2) Electricity saved or consumed (unit: KWh, MWh, GWh)

Set the electricity saved in enterprise $\mathrm{E}_{1}$ as $Q_{1}$; Enterprise $\mathrm{E}_{2}$ does not save electricity, but consumes electricity, so the electricity consumed by enterprise $\mathrm{E}_{2}$ can be set as $Q_{2}$; When EPP is implemented for Enterprise $\mathrm{E}_{3}$, electric energy is saved; when EPP is not implemented, electric energy is consumed, we set the electricity saved by enterprise $\mathrm{E}_{3}$ as $Q_{3}$. The sum of electricity saved or used by the three types of enterprises is $Q$.

In addition, we can set $\lambda\left(0<\lambda^{<}\right)$as the probability, tendency or strength of enterprise $\mathrm{E}_{3}$ to implement EPP, so the probability of not implementing EPP is ' $1-\lambda$ '.

(3) Price (the price of unit of electricity saving by EPP, not the price in electricity market)

In fact, the electricity reduced by implementing EPP has exactly the same function as the electricity generated by the power plant, and the products can be completely replaced. But unlike price in electricity market, which is controlled by the government, we assume that the price of electricity reduced by EPP is affected by market supply and demand, and its price can be expressed as $\mathrm{P}(P=a-b q)$, in which $\alpha$ is the market acceptable price caps, $b$ is the market demandback coefficient. The larger the demand-back coefficient is, the smaller the market is.

\section{(4) Cost}

It is assumed that the cost of EPP implementation is mainly divided into two parts: $R \& D$ cost $C_{1}$ and operation cost $\mathrm{C}_{2}$. R\&D cost includes the costs of key processes, technologies and equipment of EPP; Operating costs include energy efficient processes and equipment produced or purchased for EPP implementation, as well as personnel inputs, etc. For enterprise $E_{1}$ and $E_{3}$, unit $R \& D$ cost and unit operation cost decrease with the increase of power saving. For enterprise $E_{2}$, this kind of enterprise has no $R \& D$ cost but only has operation cost.

(5) Carbon quotas

Assuming that the carbon quota stipulated by the government for each enterprise is $\mathrm{H}$. The government will subsidize the carbon quota of $\mathrm{h}$ for every $1 \mathrm{kwh}$ of electric quantity reduced by EPP. The government

Table 2. Variables and meanings in the assumptions.

\begin{tabular}{|c|c|c|c|}
\hline & Enterprise $\mathrm{E}_{1}$ & Enterprise $\mathrm{E}_{2}$ & Enterprise $\mathrm{E}_{3}$ \\
\hline Electricity saved & $Q_{1}$ & $Q_{2}$ & $Q_{3}$ \\
\hline Research and development costs & $C_{1}$ & 0 & $C_{1}$ \\
\hline Operating costs & $C_{2}$ & $C_{2}$ & $C_{2}$ \\
\hline Initial carbon quota & $\mathrm{H}$ & $\mathrm{H}$ & $\mathrm{H}$ \\
\hline Carbon quota for saving electricity per unit & $\mathrm{h}$ & $-\mathrm{h}$ & - \\
\hline Carbon quota revenue for saving electricity per unit & $\mathrm{d}$ & $\mathrm{d}$ & - \\
\hline The probability of choosing to implement EPP & 1 & 0 & $\lambda$ \\
\hline
\end{tabular}




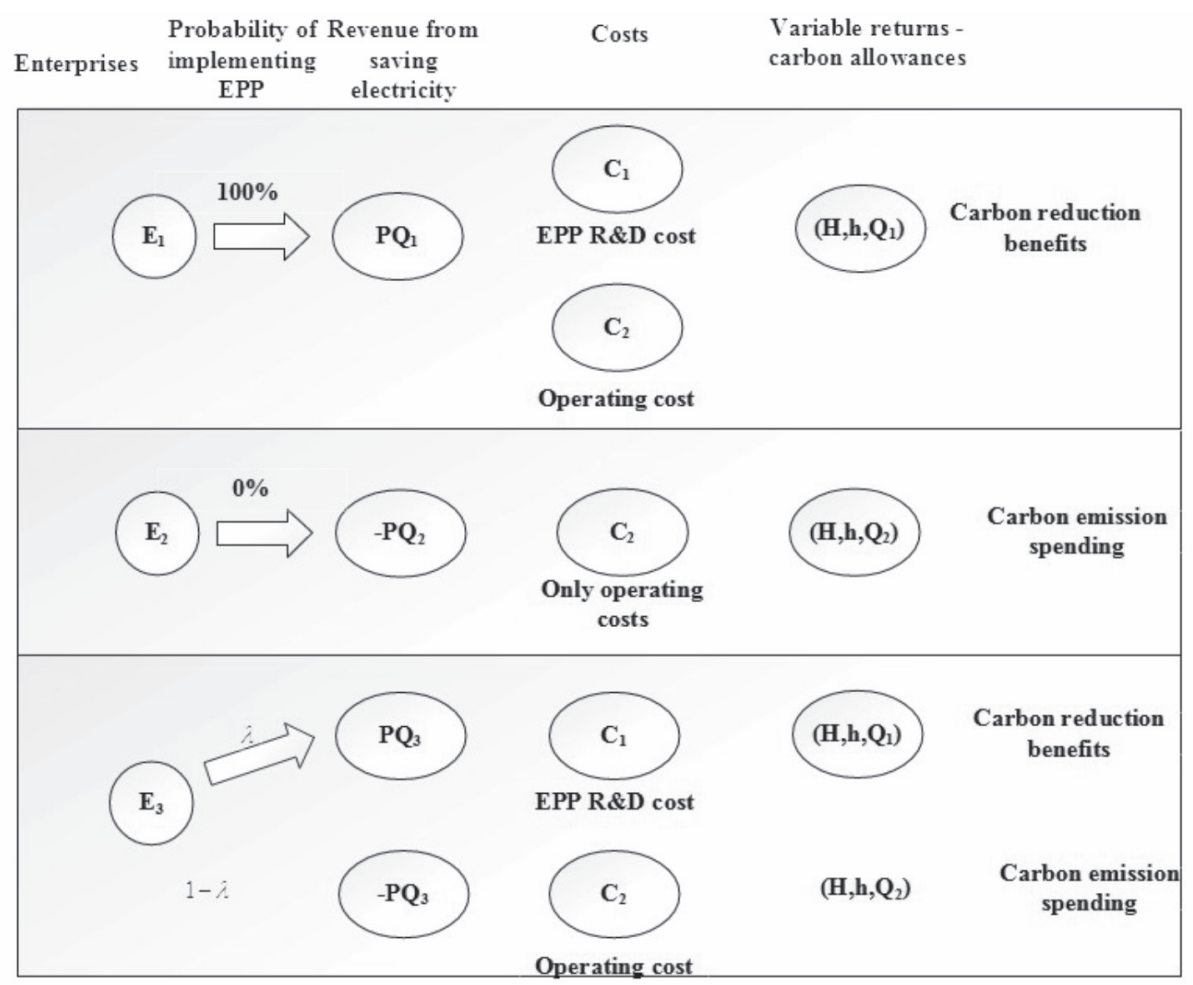

Fig. 1. The revenue, costs and variable returns of three different kinds of enterprises implementing EPP.

will deduct the carbon quota of $\mathrm{h}$ for every $1 \mathrm{kWh}$ of electric quantity consumed by the enterprise without EPP. The carbon quota can be sold or purchased, and the economic benefit of carbon quota of $h$ units is $d$.

The main parameters and implications of the above assumptions can be represented in Table 2 and the revenue, costs and variable returns of three different kinds of enterprises implementing EPP are presented in Fig. 1.

\section{Building the Profit Functions}

(1) Business revenue functions for three types of enterprises

1) Set $\pi_{1}$ as the profit function of enterprise $E_{1}$, according to the hypothesis, then

$$
\pi_{1}=P Q_{1}+h d Q_{1}+\frac{H}{h} d-C_{1}-C_{2} Q_{1}
$$

Put $(P=a-b q), Q=Q_{1}+Q_{2}+Q_{3}$ into formula (1) to get:

$\pi_{1}=a Q_{1}-b Q_{1}^{2}-b Q_{1} Q_{2}-b Q_{1} Q_{3}+h d Q_{1}+\frac{H}{h} d-C_{1}-C_{2} Q_{1}$

Take the derivative of $Q_{1}$ first order and set it equal to 0 in formula (1),

$$
\frac{\partial \pi_{1}}{\partial Q_{1}}=a-2 b Q_{1}-b Q_{2}-b Q_{3}+h d-C_{2}=0
$$

Thus, the optimal power saving $Q_{1}^{*}$ can be obtained

$$
Q_{1}^{*}=\frac{a-b Q_{2}-b Q_{3}+h d-C_{2}}{2 b}
$$

2) Set $\pi_{2}$ as the revenue function of enterprise $E_{2}$, according to the hypothesis, then

$$
\pi_{2}=P Q_{2}+\frac{H}{h} d-h d Q_{2}-C_{2} Q_{2}
$$

In the same way, take the derivative of $Q_{2}$ first order and set it equal to 0 in formula (5). Thus, the optimal power consumption $Q_{2}{ }^{*}$ of enterprise $\mathrm{E}_{2}$ can be obtained

$$
Q_{2}^{*}=\frac{a-b Q_{1}-b Q_{3}-h d-C_{2}}{2 b}
$$

3) Set $\pi_{3}$ as the revenue function of enterprise $E_{2}$, according to the hypothesis, then

$$
\pi_{3}=P Q_{3}+\frac{H}{h} d+\lambda Q_{3} h d-(1-\lambda) Q_{3} h d-C_{1}-C_{2} Q_{3}
$$


In the same way, take the derivative of $Q_{3}$ first order and set it equal to 0 in formula (7). Thus, the optimal power consumption $Q_{3}{ }^{*}$ of enterprise $\mathrm{E}_{3}$ can be obtained

$$
Q_{3}^{*}=\frac{a-b Q_{1}-b Q_{2}+2 \lambda h d-h d-C_{2}}{2 b}
$$

Joint establishment of optimal power consumption of three kinds of enterprises, and it can be simplified to

$$
\left\{\begin{array}{l}
Q_{1}^{*}=\frac{a-2 \lambda h d+5 h d-C_{2}}{4 b} \\
Q_{2}^{*}=\frac{a-2 \lambda h d-3 h d-C_{2}}{4 b} \\
Q_{3}^{*}=\frac{a+6 \lambda h d-3 h d-C_{2}}{4 b} \\
Q^{*}=\frac{3 a+2 \lambda h d-h d-3 C_{2}}{4 b}
\end{array}\right.
$$

By substituting the optimal solution of the above formula into the profit function of the respective enterprises, the optimal earnings of the three types of enterprises can be further obtained as follows:

$$
\left\{\begin{array}{c}
\pi_{1}{ }^{*}=\frac{\left(a-2 \lambda h d+5 h d-C_{2}\right)^{2}}{16 b}+\frac{H d}{h}-C_{1} \\
\pi_{2}{ }^{*}=\frac{\left(a-2 \lambda h d-3 h d-C_{2}\right)^{2}}{16 b}+\frac{H d}{h} \\
\pi_{3}{ }^{*}=\frac{\left(a+6 \lambda h d-3 h d-C_{2}\right)^{2}}{16 b}+\frac{H d}{h}-C_{1}
\end{array}\right.
$$

\section{Results and Discussion}

\section{Relationship Analysis of Main Parameters}

\section{(1) For enterprises $E_{1}$}

According to Formula (9), the electricity saved by enterprise $\mathrm{E}_{1}$ has no relationship with the total carbon quota $(\mathrm{H})$ set by the government for the enterprise, and is related to the carbon quota (h) obtained by saving each unit of electricity and the benefit (d) of unit carbon quota. In formula (9), the optimized first-order derivative of $Q_{1}^{*}$ to $\mathrm{h}$ can be obtained as follows:

$$
\frac{\partial Q_{1}^{*}}{\partial h}=\frac{5 d-2 \lambda d}{4 b}
$$

Then Result 1 and Result 2 can be obtained as below.
Result 1: for enterprise $E_{1}$, the electricity saved is positively correlated with the carbon quota $\mathrm{h}$ obtained, and the sales volume increases with the increase of unit carbon quota $\mathrm{h}$. Similarly, the sales volume $Q_{1}$ of enterprise $\mathrm{E}_{1}$ is positively correlated with the revenue obtained from unit carbon quota, which increases with d.

Result 2: The income of enterprise $\mathrm{E}_{1}$ is directly related to the carbon quota. There is a unit of carbon quotas $h_{0}$, when the carbon quota obtained by EPP is higher than $h_{0}$, the income of enterprise $\mathrm{E}_{1}$ will increase with unit carbon quota, and enterprise $\mathrm{E}_{1}$ will continuously increase its sales volume to obtain greater income; When the carbon quota obtained from EPP is lower than $h$, the enterprise income decreases with unit carbon quota, and the enterprise reduces the intensity of EPP to ensure its own interests within a reasonable range.

Then, we analyze the relationship between the profit and $R \& D$ investment. The optimized first derivative of revenue $\pi_{1}$ with respect to R\&D investment $C_{1}$ can be obtained as follows:

$$
\frac{\partial \pi_{1}}{\partial C_{1}}=-1
$$

Then Result 3 can be obtained as below.

Result 3: In Formula (12), $\frac{\partial \pi_{1}}{\partial C}<0$, therefore, for enterprise $\mathrm{E}_{1}$, its incomes are negatively correlated with $R \& D$ investment, and enterprise income $\pi_{1}$ decreases with R\&D investment $C_{1}$. In order to ensure the normal operation of the enterprise, there must be a critical value of the $R \& D$ investment. Below this value, the enterprise can operate normally and obtain profits. If the $R \& D$ investment exceeds this value, the enterprise will be unprofitable.

Then we analyze the relationship between income $\pi_{1}$ of enterprise $E_{1}$ and income $d$ from unit carbon quota. In formula (10), the optimized first derivative of enterprise income with respect to unit carbon quota income can be obtained as follows:

$$
\frac{\partial \pi_{1}}{\partial d}=\frac{(10-4 \lambda) a h+8 \lambda^{2} h^{2} d+(50-40 \lambda) h^{2} d+4 \lambda h C_{2}}{16 b}+\frac{H}{h}
$$

Then Result 4 can be obtained as below.

Result 4: In formula (13), all the unknowns are positive values, and as $0<\lambda<1$, then $(10-4 \lambda) a h>0$, $(50-40 \lambda) h^{2} d>0$, and so $\frac{\partial \pi_{1}}{\partial d}>0$. There is a positive correlation between the income of enterprise $\mathrm{E}_{1}$ and the income of unit carbon quota, that is, with the increase of the income of unit carbon quota formulated by the government, the income of enterprises is gradually increasing. Similarly, the income of enterprise $E_{1}$ is positively correlated with the total carbon quota set by 
the government, and the higher the carbon quota set by the government, the higher the profit obtained by the enterprise.

(2) For enterprises $E_{2}$

In Formula (9), the first derivative of electricity quantity $Q_{2}$ consumed by enterprise $\mathrm{E}_{2}$ with respect to carbon quota $\mathrm{h}$ and revenue $\mathrm{d}$ of unit carbon quota can be obtained as follows:

$$
\left\{\begin{array}{l}
\frac{\partial Q_{2}}{\partial h}=-\frac{2 \lambda d+3 d}{4 b} \\
\frac{\partial Q_{2}}{\partial d}=-\frac{2 \lambda h+3 h}{4 b}
\end{array}\right.
$$

Then Result 5 can be obtained as below.

Result 5: Since $\lambda, \mathrm{d}, \mathrm{h}$, and b are all constants greater than 0 , the right side of formula (14) is greater than 0 , and the left side is less than 0 . This means that electric quantity consumed by enterprise $\mathrm{E}_{2}$ is negatively correlated with carbon quota $\mathrm{h}$ and income $\mathrm{d}$ of unit carbon quota.

Next, we only study income of enterprise $E_{2}$, which is directly related to the total amount of carbon quota, the carbon quota consumed and the income of unit carbon quota. In formula (10), the optimized first-order derivative of revenue $\pi_{2}$ of enterprise $E_{2}$ with respect to revenue $\mathrm{d}$ of unit carbon quota can be obtained as follows:

$\frac{\partial \pi_{2}}{\partial d}=\frac{-(6+4 \lambda) a h+8 \lambda^{2} h^{2} d+24 \lambda h^{2} d+4 \lambda h C_{2}+18 h^{2} d+6 h C_{2}}{16 b}+\frac{H}{h}$

We can't determine if $\frac{\partial \pi_{2}}{\partial d}$ is greater than 0 in formula (15). Let $\frac{\partial \pi_{2}}{\partial d}=0$, we can get:

$$
d_{0}=-\frac{16 b h}{8 \lambda^{2} h^{3}+24 \lambda h^{3}+18 h^{2}}+\frac{6 a+4 \lambda a+4 \lambda C_{2}+6 h}{8 \lambda^{2} h+24 \lambda h+18 h}
$$

In formula (16), when $d=d_{1}, \frac{\partial \pi_{2}}{\partial d}=0$. Therefore, the second derivative of formula (15) can be obtained as follows:

$$
\frac{\partial^{2} \pi_{2}}{\partial d^{2}}=\frac{8 \lambda^{2} h^{2}+24 h^{2}+18 \lambda h^{2}}{16 b}
$$

Then Result 6 is obtained as below.

Result 6: In formula (17), $\mathrm{h}$ and $\mathrm{b}$ are constants greater than $0,0<\lambda<1$. That is $\frac{\partial^{2} \pi_{2}}{\partial d^{2}}>0$, the second derivative is greater than 0 , indicating that the first derivative is monotonically increasing function. When $d>d_{0}$, the first derivative is greater than 0 , and the first derivative is a monotone increasing function. Therefore, the original function $\pi_{2}$ is a monotone increasing function, that is, enterprise $\mathrm{E}_{2}$ and income $\pi_{2}$ increase with income $\mathrm{d}$ of unit carbon quota. When $d<d_{0}$, the first derivative is less than 0 , that is, the original function $\pi_{2}$ is a monotone decreasing function, and the enterprise income $\pi_{2}$ decreases with income $d$ of unit carbon quota. Enterprise $\mathrm{E}_{2}$ income decreases firstly and then increases with carbon quota income, and when $d=d_{1}$, enterprise income is the smallest.

Similarly, in order to study the relationship between enterprise $E_{2}$ income $\pi_{2}$ and carbon quota $h$ consumption, the modeling process is similar to the above contents. Take the second derivative of income $\pi_{2}$ and carbon quota $\mathrm{h}$ of consumption, $h_{0}$ can be obtained; make $\frac{\partial \pi_{2}}{\partial h}=0$, and then judge the monotonicity of the function, Result 7 can be obtained as below.

Result 7: There is a negative correlation between enterprise $\mathrm{E}_{2}$ income and consumed carbon quota, that is, the income decreases with unit carbon quota. Within a certain range of unit carbon quota $h$, enterprise $E_{2}$ income will increase with carbon quota consumed, but beyond a certain range, enterprise income will decrease with carbon quota consumed. For the government, the carbon quota of $\mathrm{E}_{2}$ per unit enterprise determined must be greater than $h_{0}$, so that enterprises can be urged to reduce energy consumption in traditional production and then transform to implement EPP.

(2) For enterprises $\mathrm{E}_{3}$

In this part, we analyze the electricity saved and the revenue from enterprise $E_{3}$, discuss how the parameter changes with carbon quota, and the value of the probability $\lambda$ of implementing EPP, so as to maximize the enterprise's revenue. That is, to analyze the variation trend between electricity saved and carbon quota $h$, revenue $d$ per unit carbon quota and probability $\lambda$ of EPP implementation.

Firstly, in formula (9), the first derivative of electricity quantity $Q_{3}$ consumed by enterprise with respect to carbon quota $h$ and revenue $d$ of unit carbon quota can be obtained as follows:

$$
\left\{\begin{array}{l}
\frac{\partial Q_{3}}{\partial h}=\frac{12 \lambda d-6 d}{8 b} \\
\frac{\partial Q_{3}}{\partial d}=-\frac{12 \lambda h-6 h}{8 b}
\end{array}\right.
$$

Then Result 8 can be obtained as below.

Result 8: In formula (18), $\mathrm{h}, \mathrm{d}$ and $\mathrm{b}$ are constants greater than 0 , and $0<\lambda<1$. When $0<\lambda<0.5,12 \lambda d-6 d<0$, $12 \lambda h-6 h<0$, that is $\frac{\partial Q_{3}}{\partial h}>0, \frac{\partial Q_{3}}{\partial d}>0$, the electricity saved by enterprise $\mathrm{E}_{3}$ decreases with unit carbon quota $\mathrm{h}$ and unit carbon quota income $\mathrm{d}$; when $0.5<\lambda<1$, $12 \lambda d-6 d>0,12 \lambda h-6 h>0$, that is $\frac{\partial Q_{3}}{\partial h}>0, \frac{\partial Q_{3}}{\partial d}>0$, the 
electricity saved by enterprise $E_{3}$ increases with unit carbon quota $\mathrm{d}$ and unit carbon quota revenue $\mathrm{d}$.

Secondly, we analyze the income in formula (10) of enterprise $\mathrm{E}_{3}$, and find that the factors affecting enterprise income are related to the development cost, the total carbon quota given by the government, the income of carbon quota per unit, and the carbon quota obtained (or consumed) from energy saving (consumption). The relationship between enterprise income and unit carbon quota income is analyzed as below.

In Formula (10), the first derivative of enterprise income $\pi_{3}$ with respect to revenue $\mathrm{d}$ of unit carbon quota can be obtained as follows:

$\frac{\partial \pi_{3}}{\partial d}=\frac{12 \lambda a h-6 a h+72 \lambda^{2} h^{2} d-72 \lambda h^{2} d+18 h^{2} d+6 h C_{2}-12 \lambda h C_{2}}{16 b}+\frac{H}{h}$

We can't determine whether $\frac{\partial \pi_{3}}{\partial d}$ is greater than 0 in formula (19). Therefore, the second derivative of $d$ can be obtained as follows:

$$
\frac{\partial^{2} \pi_{3}}{\partial d^{2}}=\frac{72 \lambda^{2} h^{2}-72 \lambda h^{2}+18 h^{2}}{16 b}
$$

In formula (20), $\mathrm{h}$ and $\mathrm{b}$ are constants greater than 0 , and $0<\lambda<1$,so whether $\frac{\partial^{2} \pi}{\partial d^{2}}$ is greater than 0 is equal to whether $72 \lambda^{2} h^{2}-72 \lambda h^{2}+18 h^{2}$ is greater than 0 . Because $h^{2}$ must be greater than 0 , so we just need to determine whether $72 \lambda^{2} h^{2}-72 \lambda h^{2}+18$ is greater than 0 . Let $72 \lambda^{2} h^{2}-72 \lambda h^{2}+18=0$, we get $\lambda=12$, in other words, this quadratic opens up and only intersects the $\mathrm{X}$-axis at one point. Therefore, it can be concluded that $\frac{\partial^{2} \pi_{3}}{\partial d^{2}} \geq 0$ is always true, that is, the first derivative function is monotonically increasing function. Set the first derivative function equal to 0 , and we can get $d_{0}^{\prime}$ :

$$
d_{0}^{\prime}=-\frac{8 H b}{36 \lambda^{2} h^{3}-36 \lambda h^{3}+9 h^{3}}-\frac{2 a \lambda-a+C_{2}-2 \lambda C_{2}}{12 \lambda^{2} h-12 \lambda h+3 h}
$$

Then Result 9 can be obtained as below.

Result 9:When $d<d_{0}^{\prime}, \frac{\partial \pi_{3}}{\partial d}<0$, and the second derivative function $\frac{\partial^{2} \pi_{3}}{\partial d^{2}}$ is a monotone increasing function, so the original function $\pi_{3}$ is a monotonically decreasing function. That is, enterprise $\mathrm{E}_{3}$ income $\pi_{3}$ is negatively correlated with unit carbon quota income $\mathrm{d}$, and enterprise income decreases with unit carbon quota income. When $d<d_{0}^{\prime}, \frac{\partial \pi_{3}}{\partial d}<0$, and the second derivative function $\frac{\partial^{2} \pi_{3}}{\partial d^{2}}$ is a monotone increasing function, so the original function $\pi_{3}$ is a monotonically increasing function. In other words, enterprise $\mathrm{E}_{3}$ income $\pi_{3}$ increases with unit carbon quota income $\mathrm{d}$. With the increase of unit carbon quota income, enterprise $\mathrm{E}_{3}$ income shows a trend of decreasing firstly and then increasing, and when unit carbon quota income $d=$ $d_{0}^{\prime}$, the enterprise income is the lowest. When $d<d_{0}^{\prime}$, enterprise income decreases with unit carbon quota. The main reason is that enterprises are unwilling to implement EPP in the early stage, and the higher the income of unit carbon quota increases, the higher the government punishment enterprises will accept. When $d>d_{0}^{\prime}$, the enterprise begins to implement EPP, and the increase of unit carbon quota income will greatly increase the income brought by power saving, so the enterprise income will gradually increase.

Similarly, the change trend between enterprise benefit and unit carbon quota $h$ is as same as the relationship between enterprise income and unit carbon quota income $\mathrm{d}$, so the analysis process can be omitted. The result is, enterprise $\mathrm{E}_{3}$ income will decrease firstly and then increase with unit carbon quota, and when $\mathrm{h}=h_{0}$, the income reaches the minimum value.

Next, we analyze the relationship between corporate income and total carbon quota. In formula (10), the first derivative of enterprise $\mathrm{E}_{3}$ income $\pi_{3}$ with respect to the total carbon quota $\mathrm{H}$ can be obtained as follows:

$$
\frac{\partial \pi_{3}}{\partial H}=\frac{d}{h}
$$

Then Result 10 can be obtained as below.

Result 10: In formula (22), $\mathrm{d}$ and $\mathrm{h}$ are constants greater than 0 , so $\frac{\partial \pi_{3}}{\partial H}>0$, and the original function is a monotonically increasing function. In other words, there is a positive correlation between enterprise $E_{3}$ income $\pi_{3}$ and total carbon quota $H$. Enterprise $E_{3}$ income increases with total carbon quota given by the government.

Then the first derivative of enterprise $\mathrm{E}_{3}$ income $\pi_{3}$ with respect to the probability $\lambda$ of EPP implementation can be obtained as follows:

$$
\frac{\partial \pi_{3}}{\partial \lambda}=\frac{3 h d(a+6 \lambda h d)-3 h d-C_{2}}{4 b}
$$

In formula (23), we can't determine whether $\frac{\partial \pi_{3}}{\partial \lambda}$ is greater than 0 , so the second derivative of $\lambda$ can be obtained as follows:

$$
\frac{\partial^{2} \pi_{3}}{\partial \lambda^{2}}=\frac{27 h^{2} d^{2}}{2 b}
$$

In formula (24), h, d and b are constants greater than 0 , so $\frac{\partial^{2} \pi_{3}}{\partial \lambda^{2}}>0$. The first derivative $\frac{\partial \pi_{3}}{\partial \lambda}$ is a 
Table 3. The value setting of some parameters in simulation.

\begin{tabular}{|c|c|c|c|c|c|c|}
\hline $\mathrm{a}$ & $\mathrm{b}$ & $C_{1}$ & $C_{2}$ & $\mathrm{H}$ & $\mathrm{h}$ & $\mathrm{d}$ \\
\hline 10 & 2 & 3 & 2 & 5 & 0.03 & 0.2 \\
\hline
\end{tabular}

monotonically increasing function. Let $\frac{\partial \pi_{3}}{\partial \lambda}=0$, we get $\lambda_{0}$ :

$$
\lambda_{0}=\frac{C_{2}+3 h d-a}{6 h d}
$$

Then Result 11 can be obtained as below.

Result 11: When $\lambda<\lambda_{0}, \frac{\partial \pi_{3}}{\partial \lambda}<0$, and the first derivative function is monotone increasing function. Therefore, the function $\pi_{3}$ is a monotone decreasing function, and enterprise $\mathrm{E}_{3}$ earnings $\pi_{3}$ decreases with $\lambda$. When $\lambda>\lambda_{0}$, the first derivative is a monotone increasing function, and $\frac{\partial \pi_{3}}{\partial \lambda}<0$, the function $\pi_{3}$ is a monotonically increasing function, that is, enterprise $\mathrm{E}_{3}$ earnings $\pi_{3}$ increases with of $\lambda$. In the change process of probability $\lambda$ of implementing EPP, enterprise income first gradually decreases and then increases. The previous enterprise income will decrease with the increase of $\lambda$, the main reason lies in the large investment in the research and development of EPP technology and equipment in the early stage. With the increase of $\lambda$, EPP is gradually recognized and promoted by the government and enterprises due to its advantages of zero emission and energy saving. After a period of promotion and gradual improvement of government policies, the benefits brought to enterprises by the implementation of EPP are gradually reflected. Therefore, when $\lambda>\lambda_{0}$, enterprise income will increase

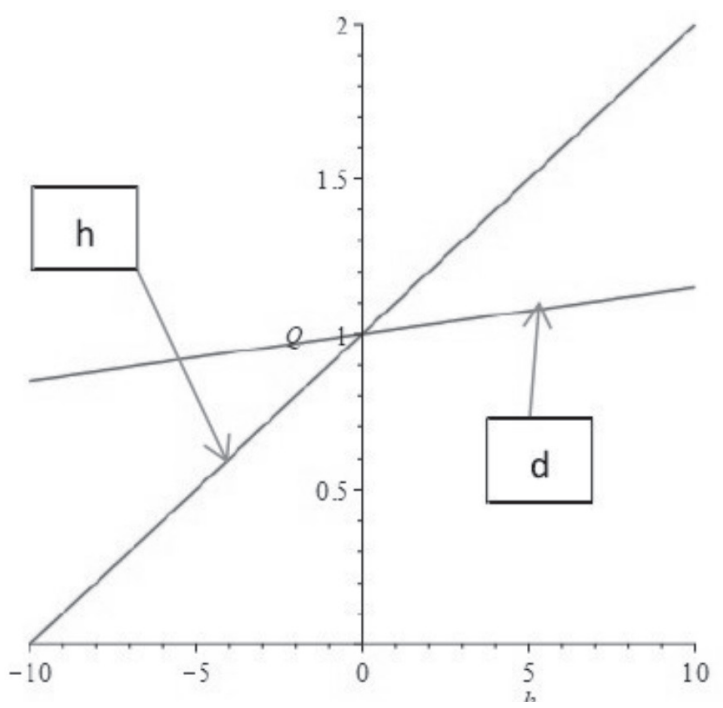

Fig. 2. The relationship between electricity $Q_{1}$ saving in enterprise $\mathrm{E}_{1}$ with $\mathrm{h}$ and $\mathrm{d}$. with $\lambda$. For enterprise $E_{3}, \lambda$ should not be set as $\lambda_{0}$, because the enterprise income is the lowest at this time; If the enterprise prefers not to implement EPP, the ratio $\lambda$ should be set below $\lambda_{0}$; If the enterprise is inclined to implement EPP, the production ratio $\lambda$ should be set above $\lambda_{0}\left(0<\lambda_{0}<1\right)$. The higher the proportion is set, the greater the profit of the enterprise will be.

\section{Results Verifying}

The previous 11 results are mainly obtained through mathematical model construction and derivation. In order to verify the validity of the results, this part uses Maple, a simulation software, to verify the validity of the results. Maple software is one of the most general mathematical and engineering computing software in the world, and is widely used in the field of mathematics and science. Main steps of Maple simulation include four steps, namely assignment of variables, establishment of simulation model, analysis model and conclusion. Among them, numerical setting plays a crucial role in the establishment of simulation model, which determines whether the simulation model can correctly verify the results.

According to the above parameters setting and requirements, and referring to literature [22] and [27, $28]$, we set the values of each parameter as shown in Table 3.

Now Maple software is used to verify 11 results of the changes of industry income, output and other variables of three kinds of enterprises respectively, and the verification processes are as follows.

(1) For enterprises $E_{1}$

Verify Result 1 : Let $\lambda=0.5$, and according to known parameters, draw the changing trend diagram between electric quantity $Q_{1}$ saved by enterprise $\mathrm{E}_{1}$ unit carbon quota $\mathrm{h}$ and unit carbon quota income $\mathrm{d}$, as shown in Fig. 2. According to Fig. 2, the electricity $Q_{1}$ saving of the enterprise increases with unit carbon quota $h$ and unit carbon quota income $\mathrm{d}$, which verifies the correctness of result 1. And according to Fig. 2, the slope of the image of unit carbon quota $\mathrm{h}$ is obviously greater than unit carbon quota revenue $\mathrm{d}$, that is, the influence of unit carbon quota $\mathrm{h}$ on electricity $Q_{1}$ saving is greater than unit carbon quota income $\mathrm{d}$.

Verify Result 2: The relationship image between enterprise $E_{1}$ income $\pi_{1}$ and unit carbon quota $h$ is plotted according to known conditions, as shown in Fig. 3. It can be seen that when $0<\mathrm{h}<1.4$, enterprise income decreases with the increase of unit carbon quota; When $\mathrm{h}>1.4$, enterprise income increases with the increase of unit carbon quota, and the increase amplitude is gradually expanding; When $\mathrm{h}=1.4$, the enterprise income reaches the minimum value, which is consistent with result 2 .

Verify Result 3 and Result 4: Similarly, we set $\lambda=0.5$ and plot the relationship image between enterprise $\mathrm{E}_{1}$ income $\pi_{1}, \mathrm{R} \& \mathrm{D}$ cost $C_{1}$ and unit carbon quota income d, as shown in Fig. 4. It can be seen that 


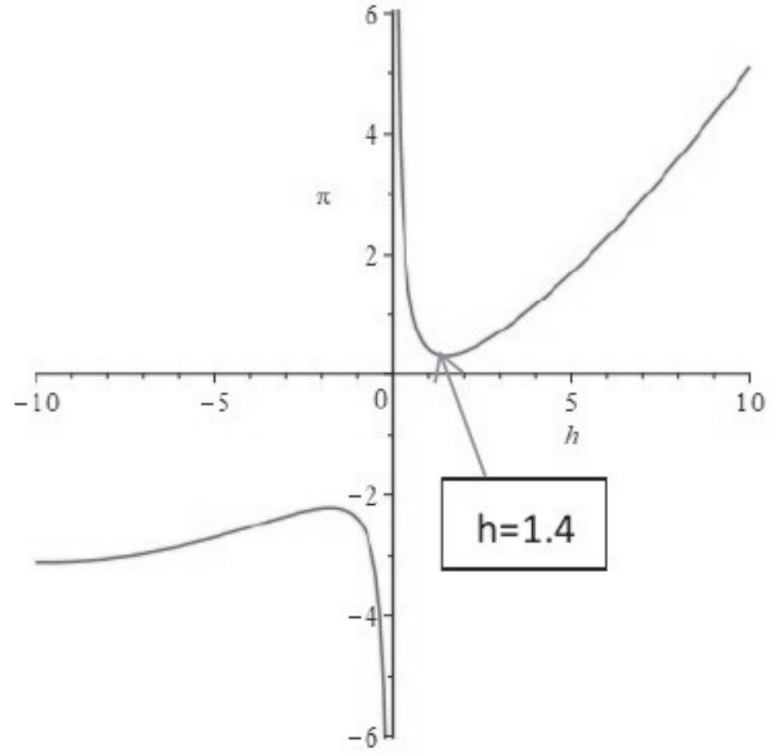

Fig. 3. The relationship between enterprise $\mathrm{E}_{1}$ income $\pi_{1}$ and $\mathrm{h}$.

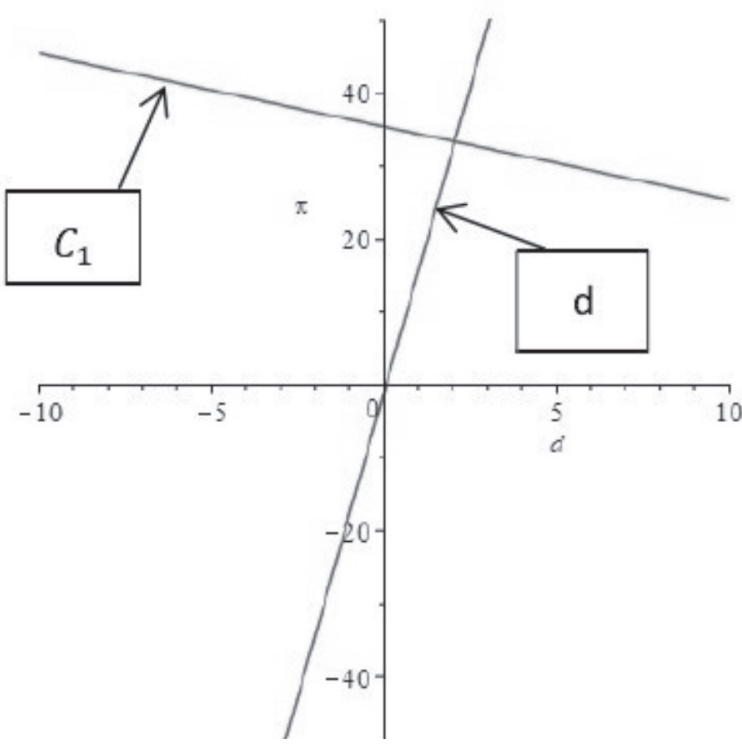

Fig. 4. The relationship between enterprise $E_{1}$ income $\pi_{1}$ with $C_{1}$ and d.

$\pi_{1}$ decreases with R\&D cost and increases with unit carbon quota income. In other words, the larger the income per unit carbon quota is, the higher the income from implementing EPP to save electricity, and the more enterprises tend to implement EPP, the more conducive to the development of EPP, which is consistent with result 3 and result 4 . It should be noted that the above situation does not hold indefinitely, because in the actual cases, the enterprise income will increase with carbon quota income over a period of time. However, after a certain range, under the influence of some factors such as policies, market saturation, diminishing marginal return and so on, enterprise income will not continue to increase with carbon quota income.

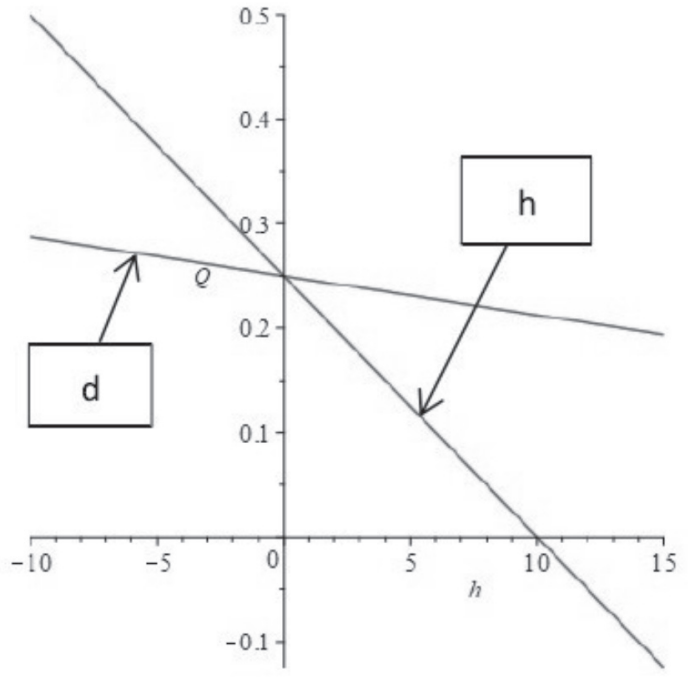

Fig. 5. The relationship between electricity $Q_{2}$ consuming in enterprise $\mathrm{E}_{2}$ with $\mathrm{h}$ and $\mathrm{d}$.

(2) For enterprises $E_{2}$

Verify Result 5: we set $\lambda=0.5$ and plot the function image between electric quantity $Q_{2}$ consumed by enterprise $E_{2}$, unit carbon quota $h$ and unit carbon quota income d, as shown in Fig. 5. According to the figure, electric quantity $Q_{2}$ consumed by enterprise $\mathrm{E}_{2}$ decreases with $d$ and $h$, which is consistent with the result 5. Moreover, the image of $h$ is steeper than that of $\mathrm{d}$, that is, the influence degree of $\mathrm{h}$ on $Q_{2}$ is greater than d. So, when two factors influence the output at the same time, the variable $\mathrm{h}$ should be given the priority.

Verify Result 6: Let $\lambda=0.5$ and draw the graph of the first-order derivative function of enterprise $\mathrm{E}_{2}$ income $\pi_{2}$ with respect to unit carbon quota income $\mathrm{d}$, as shown in Fig. 6a). According to the image, when $d>0$, the value of the first derivative function of enterprise $\mathrm{E}_{2}$ income $\pi_{2}$ with respect to unit carbon quota income $\mathrm{d}$ is constant. In other words, enterprise income is positively correlated with unit carbon quota income, which increases with unit carbon quota income. When the first derivative is equal to $0, d=d_{0}<0$, in the actual operation of an enterprise, the income per unit carbon quota will not be negative, so the function of $d<0$ is not analyzed. Plot the relationship image between enterprise $\mathrm{E}_{2}$ income $\pi_{2}$ and unit carbon quota income $\mathrm{d}$, as shown in Fig. 6b). The analysis based on Figure 6a shows that when $d>0$, enterprise income increases with unit carbon quota, which is consistent with result 6 .

Verify Result 7: Let $\lambda=0.5$ and draw the graph of the first-order derivative function of enterprise $\mathrm{E}_{2}$ income $\pi_{2}$ with respect to unit carbon quota $h$, as shown in Fig. 7. In practice, it is impossible to take a negative value of carbon quota $h$, so we draw the image when $h>0$. According to the image, when $\mathrm{h}<-0.76, \frac{\partial \pi_{2}}{\partial h}>0$, that is, enterprise $E_{2}$ income $\pi_{2}$ increases with the increase of 
a)

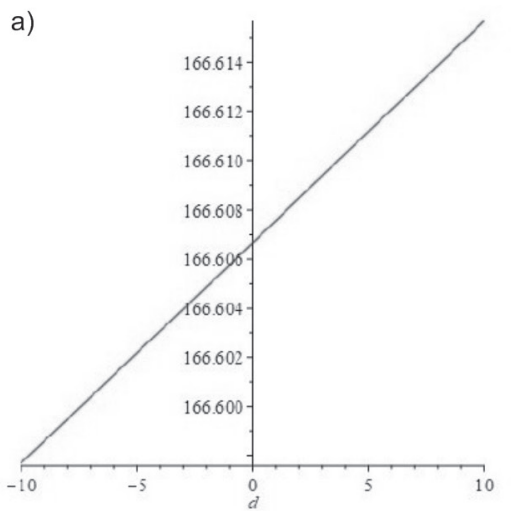

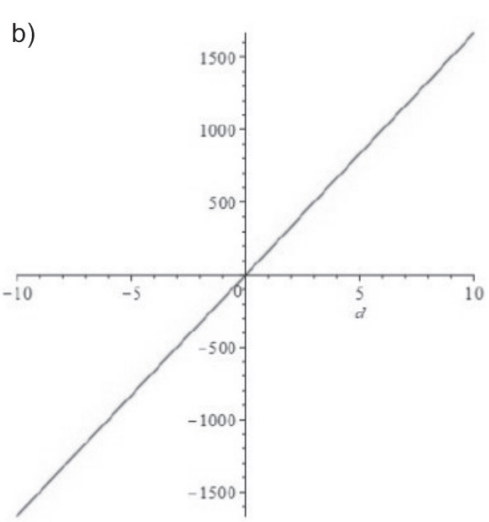

Fig. 6. a) The function image of the derivative of $\pi_{2}$ with respect to $d$; b) The relationship between $\pi_{2}$ and d.

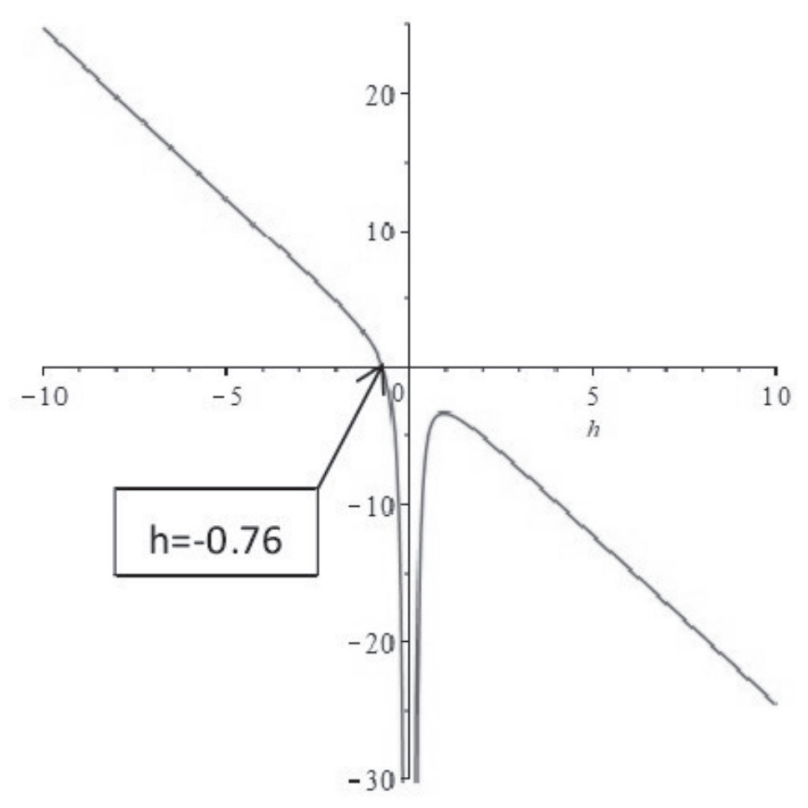

Fig. 7. The function image of the derivative of $\pi_{2}$ with respect to $h$.

a)

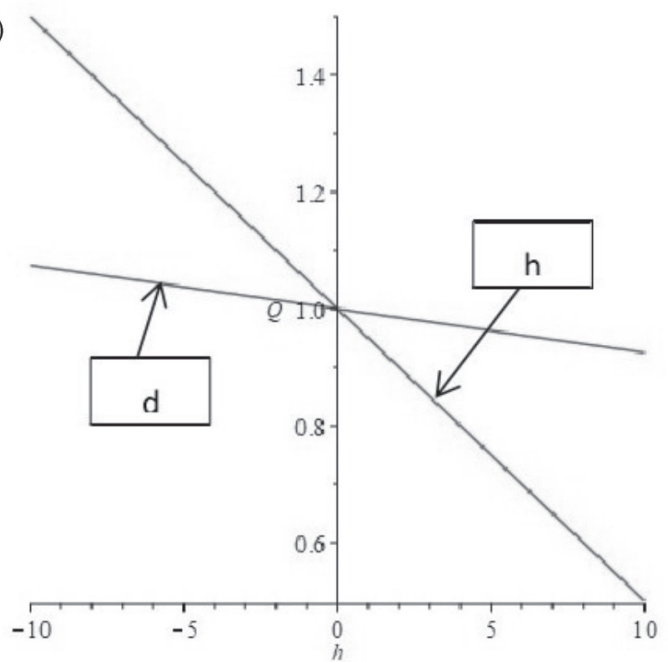

carbon quota h consumed; when $\mathrm{h}>-0.76, \frac{\partial \pi_{2}}{\partial h}<0$, that is, enterprise $\mathrm{E}_{2}$ income $\pi_{2}$ decreases with carbon quota h consumed, which is consistent with result 7.

(3) For enterprises $\mathrm{E}_{3}$

Verify Result 8: We analyze the relationship between electric quantity $Q_{3}$ saved by enterprise $\mathrm{E}_{3}$ with unit carbon quota $\mathrm{d}$ and unit carbon quota income $\mathrm{h}$. In this model, there are two stages according to whether $\lambda$ is greater than 0.5 . When $0<\lambda<0.5$, set $\lambda=\frac{1}{6}$, and draw the changing trend image of the relationship between $Q_{3}$, $\mathrm{d}$ and h. As shown in Fig. 8a), $Q_{3}$ decreases with $\mathrm{d}$ and $\mathrm{h}$, however, since the slope of curve $\mathrm{h}$ is significantly higher than that $d$, the degree of influence of $h$ is higher than $d$. When the two factors influence the output of an enterprise at the same time, the range of change of variable $\mathrm{h}$ should be given the priority. When $0<\lambda<1$, set $\lambda=\frac{2}{3}$, and draw the changing trend image of the relationship between enterprise electric saved quantity $Q_{3}, \mathrm{~d}$ and $\mathrm{h}$, as shown in Fig. 8b). $Q_{3}$ increases with $\mathrm{d}$

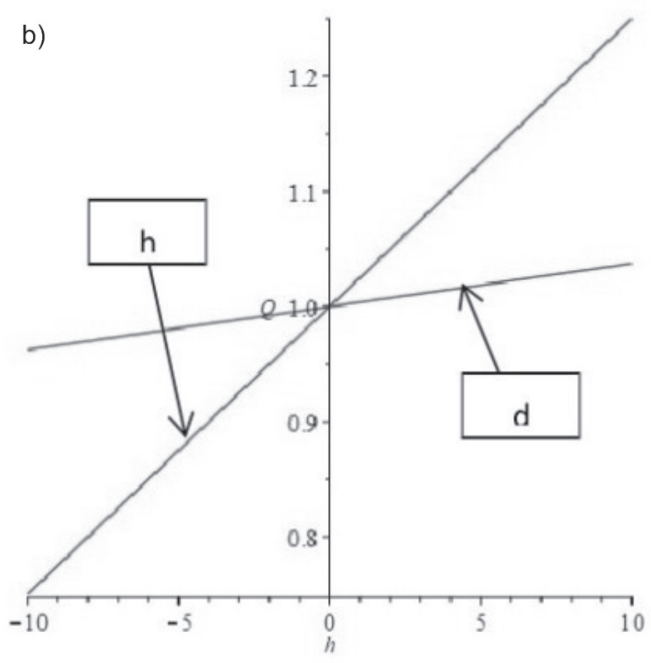

Fig. 8. a) The relationship between electricity $Q_{3}$ saving in enterprise $\mathrm{E}_{3}$ with $\mathrm{h}$ and $\mathrm{d}(0<\lambda<0.5)$; b) The relationship between electricity $Q_{3}$ saving in enterprise $\mathrm{E}_{3}$ with $\mathrm{h}$ and $\mathrm{d}(0.5<\lambda<1)$. 


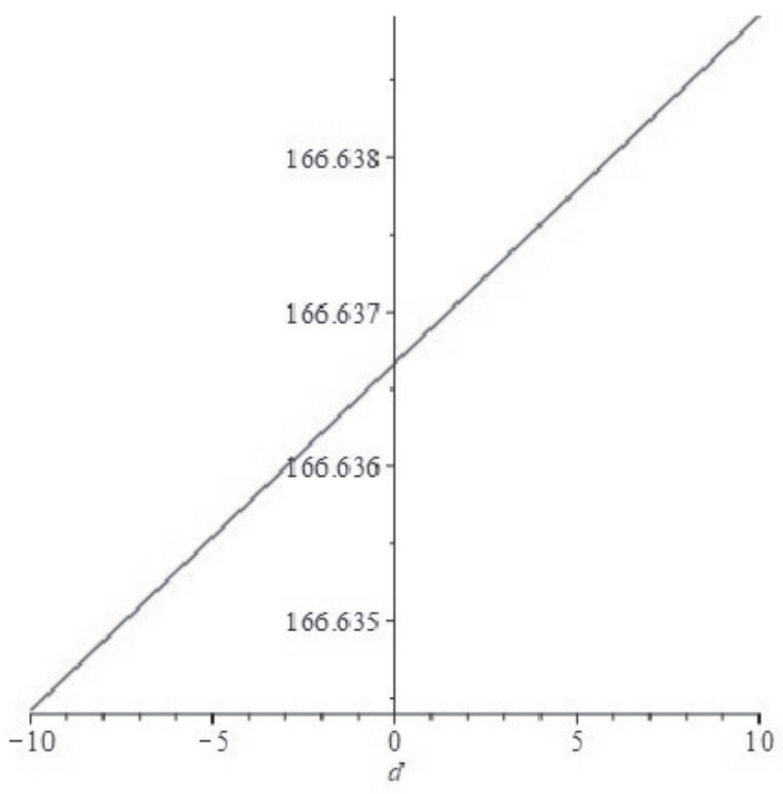

Fig. 9. The function image of the derivative of $\pi_{3}$ with respect to $\mathrm{d}$.

and h, similarly, h has a higher influence on $Q_{3}$ than $\mathrm{d}$. The result of this part is consistent with the result 8 , which verifies the correctness of the result 8 .

Verify Result 9: Study the relationship between enterprise $\mathrm{E}_{3}$ income $\pi_{3}$ and unit carbon quota revenue $\mathrm{d}$, set $\lambda=\frac{1}{6}$, and draw the first-order derivative function image of $\pi_{3}$ with respect to $d$, as shown in Fig. 9. According to the figure, when $d$ is small enough, the first-order derivative function will be less than 0 , at this time, enterprise income will decrease with unit carbon quota. Subsequently, with the gradual increase of $d$, enterprise income will increase with unit carbon quota income, which is consistent with result 9.

Verify Result 10: Now study the relationship between enterprise $\mathrm{E}_{3}$ income $\pi_{3}$ and total carbon quota

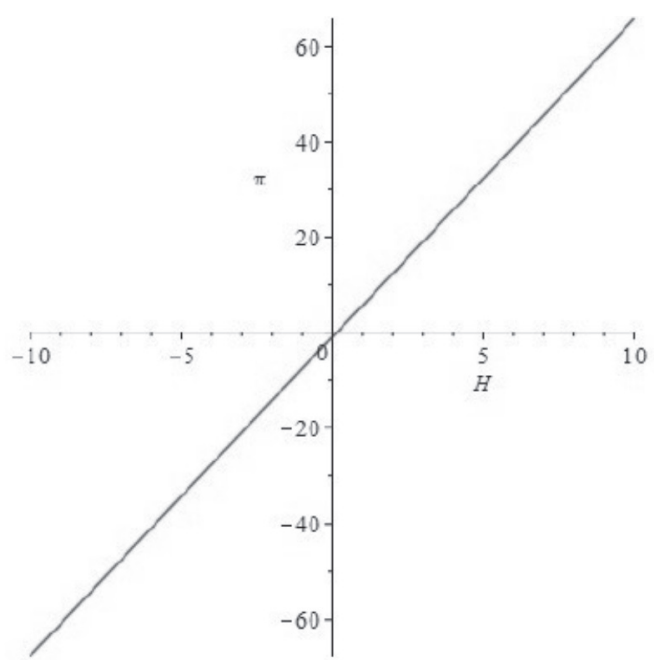

Fig. 10. the relationship between $\pi_{3}$ and total carbon quota $H$.
$\mathrm{H}$, set $\lambda=0.5$, and draw the changing trend diagram between $\pi_{3}$ and total carbon quota according to known data, as shown in Fig. 10. According to Fig. 10, the enterprise income is positively correlated with the total carbon quota, that is, the enterprise income continues to increase with the total carbon quota, which is consistent with the result 10 . In addition, for every unit of change in the total carbon quota obtained from the image, the enterprise income will change by $\frac{20}{3}$ units, that is, the total carbon quota has a great impact on the enterprise income, which is a key factor that enterprises must consider in production.

Verify Result 11: Finally, we study the relationship between enterprise $\mathrm{E}_{3}$ income $\pi_{3}$ and total carbon quota $\mathrm{h}$, set $\lambda=0.5$, and draw the changing trend diagram between $\pi_{3}$ and probability $\lambda$ to implement EPP according to known data, as shown in Fig. 11a). According to Figure 11a, the enterprise income firstly decreases and then increases with the gradual increase of $\lambda$. However, the effective value range of $\lambda$ in this paper is $0 \leq \lambda \leq 1$. Therefore, we select part of the function images in Fig. 11a) to obtain Fig. 11b), and when $0 \leq \lambda \leq 1$, the enterprise income $\pi_{3}$ continues to increase with the increase of $\lambda$ It can be seen from the figure $11 \mathrm{~b}$ that when $\lambda=0$ and the enterprise does not implement EPP, the enterprise has a certain income; and with the gradual increase of $\lambda$, the enterprise income continues to increase. When $\lambda=1$, enterprise income reaches the maximum, which is consistent with result 11 .

\section{Case Study}

To prove the practicability of the model and the results, this part will use a case study to analyze the influence on the initial total amount of carbon quota $\mathrm{H}$, carbon quota $\mathrm{h}$ obtained from unit energy saving and unit carbon quota income $\mathrm{d}$ to the probability $\lambda$ the enterprise implementing EPP. The authors and their research team members conducted a two-month field survey at four EPP projects in Jiangxi Province, China in July and August, 2019. In this part, two kind of original data are collected as below:

(1) The basic information and data of the EPP project, such as project name, investment amount, annual power saving, annual carbon emission, equipment life and other information come from field investigation of EPP project in Jiangxi province.

(2) The common parameters, such as sales price of power saved by EPP, cost of EPP implementation, and other data are referred to recent data released by authorities and Energy Statistics Yearbook.

Table 4 shows the survey object descriptions and fixed parameter setting.

Next, we will adjust the initial total amount of carbon quota $\mathrm{H}$, carbon quota $\mathrm{h}$ obtained from unit energy saving and unit carbon quota income $\mathrm{d}$, which will influence the decision of enterprises to implement $\mathrm{EPP}$, and finally calculate the power saving and income 

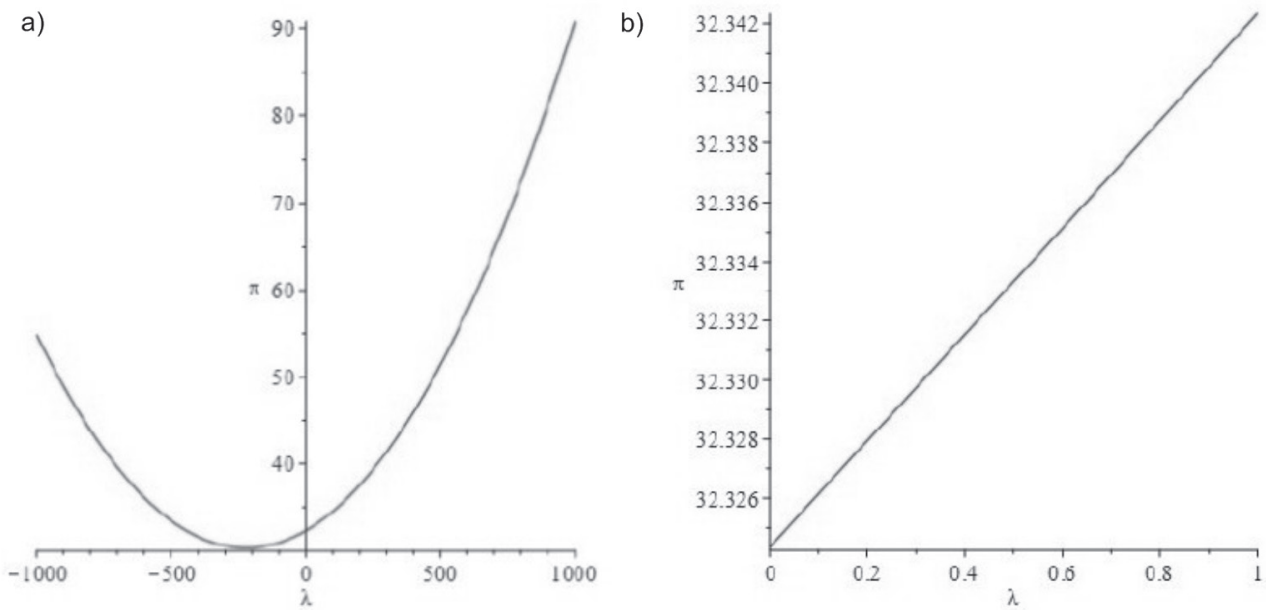

Fig. 11. a) the relationship between enterprise $E_{3}$ earnings $\pi_{3}$ and $\lambda(-10000 \leq \lambda \leq 1000)$; $\left.b\right)$ the relationship between enterprise $E_{3}$ earnings $\pi_{3}$ and $\lambda(0 \leq \lambda \leq 1)$.

of enterprises under the specified decision. Because the data in this study are complex and there is multifarious index operation, the vc++ (version 6.0) is used to construct a program to achieve the solution of this case study. The main code of $\mathrm{vc}++$ program can refer to the code in the attachment of a previous article by the author [35]. The results are shown in Table 5.

According to Table 5, lines 1 through line 3 show that unit carbon quota income $\mathrm{D}$ has a positive effect on power saving $Q$ and revenue $\pi_{3}$, with the increase of $\mathrm{d}$, enterprises are more inclined to implement EPP; Lines 4 through line 6 show that carbon quota $h$ obtained from unit energy saving has a positive effect on power saving $Q$ and revenue $\pi_{3}$, with the increase of h, enterprises are more inclined to implement EPP; Lines 7 through line 9 show that initial total amount of carbon quota $\mathrm{H}$ has a positive effect on power saving $Q$ and revenue $\pi_{3}$, with the increase of $\mathrm{H}$, enterprises are more inclined to implement EPP; lines 10 through line 12 show that $\mathrm{h}$ has a greater influence than $\mathrm{d}$, and the change of h plays a more important role in the decision of enterprises to implement EPP.

The results in Table 5 are consistent with those obtained in Part "Relationship analysis of main parameters", that is, we prove the above results from the perspective of empirical analysis.

\section{Discussion}

In this paper three important contents are put forward:

Firstly, we build the profit functions of three types of enterprises, analyze the relationships of main parameters, and get 11 results.

Secondly, we use Maple, the simulation software, to verify the validity of the results by drawing images

Table 4. The survey object descriptions and fixed parameter setting.

\begin{tabular}{|c|c|c|}
\hline Respondents & Description & Remark \\
\hline Four representative EPP projects in Jiangxi & $\begin{array}{l}\text { Two located in Nanchang City, one in Jiujiang City } \\
\text { and one in Ganzhou City }\end{array}$ & \\
\hline Basic information data & Unit & Value \\
\hline Average annual power saving (from 2015-2019) & $\mathrm{kWh}$ & $6.325 * 10^{6}$ \\
\hline${ }^{1}$ Sales price of power saved by EPP & dollar/ kWh & 0.042 \\
\hline The market power price & dollar $/ \mathrm{kWh}$ & 0.057 \\
\hline${ }^{2}$ Average annual carbon emissions & ton & 2,500 \\
\hline${ }^{3}$ Average annual cost of EPP implementation & dollar & 180,000 \\
\hline \multicolumn{3}{|c|}{ 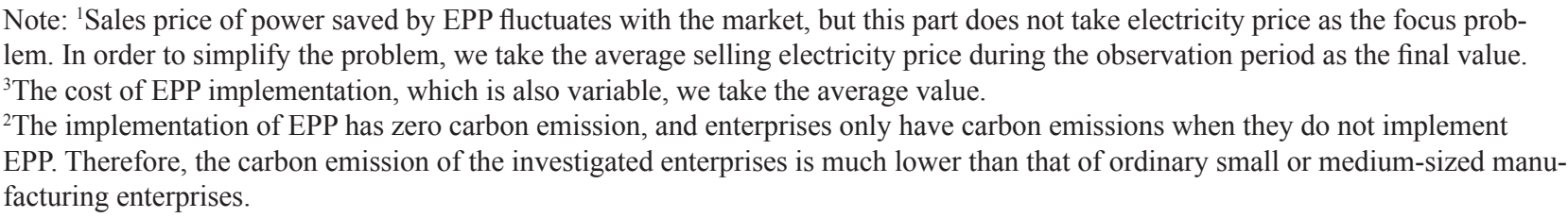 } \\
\hline
\end{tabular}


Table 5. The probability $\lambda$ of EPP implementation and its power saving $Q$ and revenue $\pi_{3}$ under different $\mathrm{H}, \mathrm{h}$ and $\mathrm{d}$.

\begin{tabular}{|c|c|c|c|c|c|}
\hline $\mathrm{H}$ (ton) & h (kg/kwh) & $\mathrm{d}($ dollar/t) & $\lambda$ & $Q\left(10^{3} \mathrm{kwh}\right)$ & $\pi_{3}\left(10^{3} \mathrm{USD}\right)$ \\
\hline 2500 & 0.11 & 15 & 0.6839 & 688 & 171.71 \\
\hline 2500 & 0.11 & 13 & 0.5050 & 634 & 156.20 \\
\hline 2500 & 0.11 & 11 & 0.4632 & 609 & 132.61 \\
\hline 2500 & 0.15 & 13 & 0.712 & 763 & 189.63 \\
\hline 2500 & 0.11 & 13 & 0.5050 & 634 & 156.20 \\
\hline 2500 & 0.07 & 13 & 0.4154 & 482 & 107.45 \\
\hline 1500 & 0.11 & 13 & 0.7021 & 742 & 175.42 \\
\hline 2500 & 0.11 & 13 & 0.5050 & 634 & 156.20 \\
\hline 3500 & 0.11 & 13 & 0.3870 & 394 & 94.31 \\
\hline 2500 & 0.15 & 11 & 0.6132 & 658 & 164.89 \\
\hline 2500 & 0.11 & 13 & 0.5050 & 634 & 156.20 \\
\hline 2500 & 0.07 & 15 & 0.4732 & 617 & 143.57 \\
\hline
\end{tabular}

of parameters. All the above 11 results passed the simulation test.

Finally, we carry out an empirical analysis of a Chinese case, and verify the practicability of the profit functions model and the results of parameter relationship analysis through the actual survey data, which has practical guiding significance.

Compared to literature [30] about the study of general low-carbon investment, low-carbon investment is translated into implementation of EPP, and specific research conclusions and specific recommendations are given; Compared to literature [25] and [29] about the income of low-carbon investment, besides the carbon emission, electricity savings are considered as one of the benefits of implementing EPP. Compared to literature [31], correlation analysis of parameters is constructed based on three different types of enterprises. Compared to literature [30] and [34], a simulation by Maple software together with a case study in China are put forward to verify the research results.

Above all, this paper has three innovation points or improvements:

First, most research objects in literatures about general low-carbon investment only have the function of reducing carbon emission or pollutant emission, while our research object-EPP in this paper is a special lowcarbon behavior, which can reduce power consumption and carbon emission at the same time.

Second, the correlation analysis of parameters we constructed takes into account not only three types of different enterprises, but also different carbon situations.

Finally, through simulation and empirical analysis, we double test the profit functions model and relevant results to verify their scientific effectiveness.

\section{Conclusion and Suggestions}

\section{Conclusion}

Firstly, the paper analyzed the factors affecting the earnings and output of EPP enterprises, non-EPP enterprises and selective EPP enterprises by establishing the profit functions; and then, we studied how the income and output of three kinds of enterprises change with the carbon quota. Thus, production decisions of different types of enterprises under different carbon quotas are obtained, and the results through Maple simulation software and empirical analysis are verified, in order to provide theoretical reference for different types of enterprises to make production decisions under different carbon quotas.

\section{Suggestions}

(1) As the carbon quota given by the government and the carbon quota obtained by implementing EPP increase, the enterprise will gain more disposable carbon quotas, so enterprises can sell excess carbon quotas to reap the benefits, and their profits will soar. At this time, enterprises should increase the investment in EPP research and input to acquisition, continuously improve the ability of EPP core technology, so as to expand their market share and obtain the long-term development of the enterprise.

(2) The effect of carbon quota obtained by implementing EPP on the output of enterprises is much greater than that of carbon quota income per unit. When both factors have an impact on the output of an enterprise, the enterprise should give priority to the carbon quota obtained by implementing EPP, so as to ensure the maximum income of the enterprise. 
(3) According to the change of carbon quota and unit carbon quota income, enterprises should adjust the intensity of EPP implementation to obtain higher income. Enterprise income is positively correlated with total carbon quota, carbon quota income per unit, and the intensity (probability) of EPP implementation. Therefore, when the total carbon quota and revenue per unit of carbon quota given by the government increase, enterprises should enhance the implementation of EPP, so that enterprises can obtain higher revenue.

\section{Acknowledgements}

This research was funded by the National Natural Science Foundation of China (NSFC, Grant No.71964022), Educational Science Project of Jiangxi Province (Grant No.18YB012), and Jiangxi Culture, Art and Science Planning Project (Grant No.YG2018037).

\section{Conflict of Interest}

The authors declare no conflict of interest.

\section{References}

1. Energy Research Institute of State Grid of China. Study on Ways and Means to the Construction of EPP; China Electric Power Press: Beijing, China, 2010 [In Chinese].

2. CHANG L.Y., HAO X.G., SONG M., WU J., FENG Y.N., QIAN Y.D., ZHANG B.N. Carbon emission performance and quota allocation in the Bohai Rim Economic Circle. Journal of Cleaner Production, 258, 120722, 2020. https:// doi.org/10.1016/j.jclepro.2020.120722

3. LI M.J., SONG C.X., TAO W.Q. A hybrid model for explaining the short-term dynamics of energy efficiency of China's thermal power plants. Applied Energy, 169, 738, 2016. https://doi:10.1016/j.apenergy.2016.02.082

4. HAYDT G., LEAL V., DIAS L. A multi-objective approach for developing national energy efficiency plans. Energy Policy, 67, 16, 2014. https://doi:10.1016/j.enpol.2013.06.133

5. ÇAKMAK R., ALTAŞ İ.H. A novel billing approach for fair and effective demand side management: Appliance level billing (AppLeBill). International Journal of Electrical Power \& Energy Systems, 121, 106062, 2020. https://doi:10.1016/j.ijepes.2020.106062

6. VENIZELOU V., MAKRIDES G., EFTHYMIOU V., GEORGHIOU G.E. Methodology for deploying costoptimum price-based demand side management for residential prosumers. Renewable Energy, 153, 228, 2020. https://doi.org/10.1016/j.renene.2020.02.025

7. WANG J.M., ZHU Y.P. Cost-benefit analysis of DSM energy-efficiency project in low-carbon vision: a case in China. Energy Education Science \& Technology, 32 (1), 645-658, 2014.

8. CHAMANDOUST H., BAHRAMARA S., DERAKHSHAN G. Day-ahead scheduling problem of smart micro-grid with high penetration of wind energy and demand side management strategies. Sustainable Energy Technologies and Assessments, 40, 100747, 2020. https:// doi.org/10.1016/j.seta.2020.100747
9. ZHU Y.P., HU Y., ZHANG F.L. Progressive IRP Models for Power Resources Including EPP. Mathematical Problems in Engineering, 2520346, 2017. https://doi. org $/ 10.1155 / 2017 / 2520346$

10. WANG J.M., ZHU Y.P., LI Y.K. EPP Energy Efficiency Calculation and Influencing Factor Analysis: Cases in China. Mathematical Problems in Engineering, 986562, 2015. https://doi.org/10.1155/2015/986562

11. WANG J.M., GE X.J., ZHANG, L.L., ZHANG, H. Management Index Systems and Energy Efficiency Diagnosis Model for Power Plant: Cases in China. Mathematical Problems in Engineering, 8159871, 2016. https://doi.org/10.1155/2016/8159871

12. CHAKRABORTY N., MONDAL A., MONDAL S. Efficient Load Control Based Demand Side Management Schemes Towards a Smart Energy Grid System. Sustainable Cities and Society, 59, 102175, 2020. https:// doi.org/10.1016/j.scs.2020.102175

13. KALAIR A.R., ABAS N., HASAN Q.U., SEYEDMAHMOUDIAN M., KHAN N. Demand Side Management in Hybrid Rooftop Photovoltaic Integrated Smart Nano Grid. Journal of Cleaner Production, 258, 120747, 2020. https://doi.org/10.1016/j. jclepro.2020.120747

14. REDDY K.S., PANWAR L.K., PANIGRAHI B.K., KUMAR R., XU Y.A. Dual Objective Approach for Aggregator Managed Demand Side Management (DSM) in Cloud Based Cyber Physical Smart Distribution System. Future Generation Computer Systems -The International Journal of Escience, 105, 843, 2020. https:// doi.org/10.1016/j.future.2017.08.019

15. MENDES D.L.D.S., RABÊLO R.DE.A.L., VELOSO A.F.S., RODRIGUES J.J.P.C., JUNIO J.V.DE.R. An adaptive data compression mechanism for smart meters considering a demand side management scenario. Journal of Cleaner Production, 255, 120190, 2020. https:/doi. org/10.1016/j.jclepro.2020.120190

16. FERNANDEZ E., HOSSAIN M.J., NIZAMI M.S.H. Gametheoretic approach to demand-side energy management for a smart neighbourhood in Sydney incorporating renewable resources. Applied Energy, 232, 245-257, 2018. https:/doi. org/10.1016/j.apenergy.2018.09.171

17. WU J.J., ZHANG J., YI W.M., CAI H.Z., LI Y., SU Z.P.A. Game-Theoretic Analysis of Incentive Effects for Agribiomass Power Generation Supply Chain in China. Energies, 14 (3), 546, 2021. https://doi.org/10.3390/ en 14030546

18. ZHANG, T., CAO S.S., PAN L.Y., ZHOU C.Y. A Policy Effect Analysis of China's Energy Storage Development Based on a Multi-Agent Evolutionary Game Model. Energies, 13 (23), 6293, 2020. https://doi.org/10.3390/ en13236293

19. YANG J., ZHANG Z.Y., HONG M., YANG M.W., CHEN J.Y. An oligarchy game model for the mobile waste heat recovery energy supply chain. Energy, 210, 118548, 2020. https://10.1016/j.energy.2020.118548

20. XIE B.C., CHEN Y.F., GAO J., ZHANG S. Dynamic environmental efficiency analysis of China's power generation enterprises: a game cross-Malmquist index approach. Environmental Science and Pollution Research, 28 (2), 1697, 2021. https://10.1007/s11356-020-10237-w

21. RAI V., BECK A.L. Play and learn: Serious games in breaking informational barriers in residential solar energy adoption in the United States. Energy Research \& Social Science, 27, 70, 2017. https://doi.org/10.1016/j. erss.2017.03.001 
22. DU S.F., ZHU J.A., JIAO H.F., YE W.Y. Game-theoretical analysis for supply chain with consumer preference to low carbon. International Journal of Production Research, 53 (12), 3753, 2015. https://doi.org/10.1080/00207543.2014.98 8888

23. DU S.F., HU L., WANG L. Low-carbon supply policies and supply chain performance with carbon concerned demand. Annals of Operations Research, 255 (1-2), 569, 2017. https://doi.org/10.1007/s10479-015-1988-0

24. CHEN H., LI Y.H., LOUIE R.H.Y., VUCETIC B. Autonomous Demand Side Management Based on Energy Consumption Scheduling and Instantaneous Load Billing: An Aggregative Game Approach. IEEE Transactions on Smart Grid, 5 (4), 1744, 2014. https://doi:10.1109/ tsg.2014.2311122

25. LI H., WANG C.X., XU L., OU W. Pricing, carbon emission reduction, collection decision, and coordination in a low-carbon closed-loop supply chain. Journal of Renewable and Sustainable Energy, 9 (6), 065907, 2017. https://doi.org/10.1063/1.4991668

26. DU S.F., ZHU L.L., LIANG L., MA F. Emissiondependent supply chain and environment-policy-making in the 'cap-and-trade' system. Energy Policy, 57, 61, 2013. https://doi.org/10.1016/j.enpol.2012.09.042

27. LUO Z., CHEN X., WANG X. The role of co-opetition in low carbon manufacturing. European Journal of Operational Research, 253 (2), 392, 2016. https://doi. org/10.1016/j.ejor.2016.02.030

28. HUANG Z.S., YU H., CHU X.Y., PENG Z.W. A novel optimization model based on game tree for multi-energy conversion systems. Energy, 150, 109, 2018. https:/doi. org/10.1016/j.energy.2018.02.091

29. SUN L.C., CAO X.X., ALHARTHI M., ZHANG J.J., TAGHIZADEH-HESARY F., MOHSIN M. Carbon emission transfer strategies in supply chain with lag time of emission reduction technologies and low-carbon preference of consumers. Journal of Cleaner Production, 264, 121664, 2020. https://doi.org/10.1016/j.jclepro.2020.121664

30. ZHU G., PAN G.Z., ZHANG W.W. Evolutionary game theoretic analysis of low carbon investment in supply chains under governmental subsidies. International journal of environmental research and public health, 15 (11), 2465, 2018. https://doi.org/10.3390/ijerph15112465
31. ARAI R., YAMAMOTO K., NISHIO T., MORIKURA M. Differential Game-Theoretic Analysis on Information Availability in Decentralized Demand-Side Energy Management Systems. Ice Trans Commun, 97 (9), 1817, 2014. https://doi.org/10.1587/transcom.e97.b.1817

32. LIU X.F., GAO B.T., WU C., TANG Y. Demand-Side Management with Household Plug-In Electric Vehicles: a Bayesian Game-Theoretic Approach. IEEE Systems Journal, 12 (3), 2894, 2017. https://doi.org/10.1109/ jsyst.2017.2741719

33. MAHMOUDI R., EMROUZNEJAD A., KHOSROSHAHI H., KHASHEI M., RAJABI, P. Performance evaluation of thermal power plants considering $\mathrm{CO}_{2}$ emission: $\mathrm{A}$ multistage PCA, Clustering, Game theory and Data Envelopment Analysis. Journal of Cleaner Production, 223, 641, 2019. https://doi.org/10.1016/j.jclepro.2019.03.047

34. DOU X., WANG J., WANG X.Y., WU L. Analysis of User Demand Side Response Behavior of Regional Integrated Power and Gas Energy Systems Based on Evolutionary Game. Proceedings of the Chinese Society of Electrical Engineering, 40 (12), 3775, 2020. https:// doi:10.13334/j.0258-8013.pcsee.190581

35. ZHU Y.P., FENG W., FAN L.Z. An evolutionary game study on implementation of Energy Efficiency Power Plants between government and enterprise considering carbon emission right trading. Applied Ecology and Environmental Research, 17 (1), 699, 2019. https://doi. org/10.15666/aeer/1701_699722

36. CASTRO M.D.F., COLCLOUGH S., MACHADO B., ANDRADE J., BRAGANÇA L. European legislation and incentives programmes for demand Side management. Solar Energy, 200 (SI), 114, 2020. https://doi:10.1016/j. solener.2019.12.004

37. DALES J.H. Pollution, Property and Prices: An Essay in Policy-making and Economics. University of Toronto Press: Toronto, Canada, 1968.

38. CHEN W.Y. Carbon quota price and CDM potentials after Marrakesh. Energy Policy, 31 (8), 709, 2003. https://doi. org/10.1016/s0301-4215(02)00122-2

39. ZHANG Y.J., WANG A.D., DA Y.B. Regional allocation of carbon emission quotas in China: Evidence from the Shapley value method. Energy Policy, 74, 454, 2014. https://doi.org/10.1016/j.enpol.2014.08.006 